\title{
Uma experiência de integração entre psiquiatria e psicanálise ${ }^{1}$
}

\section{Maria Luiza de Mattos Fiore ${ }^{2}$}

Boa tarde, agradeço o convite para participação nesta mesa e poder comentar algumas ideias a respeito de minha prática clínica no campo da saúde mental, como psiquiatra e psicanalista em um departamento de psiquiatria da EPM-UNIFESP e como membro dessa sociedade.

Sabemos que a Psicanálise começou com o atendimento das pacientes histéricas no final do século XIX. A partir dessa clínica Freud formulou seu modelo de aparelho psíquico regido pelo inconsciente e estruturado pela ação psíquica do recalcamento, sua teoria do sonho, da sexualidade e a importância do complexo de Édipo na estruturação da personalidade (Nishikawa et al, 2017).

No final do século XX, Green (1988) pergunta se a clínica do paciente borderline não desempenharia um papel equivalente à dos histéricos no começo do século, pois nota-se uma mudança nos quadros clínicos, e a psicanálise tem sido desafiada a responder a essa nova clínica do século XXI.

Após duas guerras mundiais, a capital cultural desloca-se da Europa, Paris, para a América, Nova York e cria-se a Organização Mundial de Saúde com a preocupação de compreender a distribuição mundial das doenças e os fatores de risco associados a cada enfermidade. A estatística na saúde passa cada vez mais a ser considerada (Nishikawa et al, 2017).

Na década de 50 deu-se a introdução da clorpromazina, droga mais eficaz no tratamento de processos psicóticos e o lançamento do primeiro manual diagnóstico e estatístico de transtornos mentais (DSM) da associação psiquiátrica americana.Este manual, diferentemente da tradição europeia, não seguia nem a noção de processo de doença, da psiquiatria alemã, e nem a de constituição pessoal, da escola francesa. No entanto, ainda mantinha, na sua classificação, a

\footnotetext{
${ }^{1}$ Este trabalho foi apresentado na mesa "Outro olhar: Psiquiatria, nosografia e psicanálise" com Mario Eduardo Costa Pereira no eixo "Psicanálise e suas clinicas" do I Simpósio Bienal "O mesmo, o outro: Psicanálise em movimento" da Sociedade Brasileira de Psicanálise de São Paulo.

${ }^{2}$ Membro associado da Sociedade Brasileira de Psicanálise, psiquiatra, preceptora dos programas PROPSIC e AMBORDER do Departamento de Psiquiatria da UNIFESP/EPM.
} 
oposição entre neurose e psicose e levava em conta a teoria psicanalítica (Dunker\&Kyrellos, 2011). A partir da sua terceira edição (versão corrigida publicada em 1980) há uma ruptura com essa teoria e o distúrbio mental e seu tratamento é compreendido de acordo com os princípios de testabilidade e verificação de dados segundo as pesquisas quantitativas.

Isto leva à globalização da psiquiatria norte-americana e o DSM se transforma em uma espécie de "bíblia psiquiátrica". Sua quinta edição, lançada há pouco tempo tem como propostas servir como livro-texto para estudantes de psiquiatria por meio de uma reorganização lógica, ateórica e generalizável dos transtornos mentais que pode ser aplicada a várias culturas. Seus mentores reconhecem que do ponto de vista clínico, as categorias são mais fluidas ao longo do curso da vida e buscaram introduzir abordagens dimensionais aos critérios diagnósticos. Ou seja, além de se elencar o número de sintomas existentes, procura-se dimensionar a profundidade, duração e importância de um determinado sintoma naquele paciente. Isso não resolveu totalmente o problema do diagnóstico que na sua essência continua categorial (APA, 2015) e não corresponde bem ao que se observa. Estabelece uma estrutura empírica dos transtornos tentando se harmonizar com a classificação internacional das doenças, da organização mundial de saúde (OMS), CID 10.

Como integrar a abordagem psiquiátrica atual onde o que se trata são sintomas que definem o transtorno mental, com a psicanálise que tem um método e uma teoria própria que entende o sintoma de forma diferente? Ela ainda é necessária? Acredito que sim.

A psicanálise também evoluiu e sua teoria se tornou múltipla. Temos várias possibilidades de desenvolvimentos teóricos, mas temos um só método fundante que é a escuta clínica do singular. Em minha prática como supervisora de psicoterapia de orientação psicanalítica de residentes em psiquiatria e psicólogos na universidade (UNIFESP), não nego os avanços na área de neurociências - biologia molecular, farmacologia, genética e outros. A questão que se impõe no momento, é a da ESCUTA de um indivíduo singular de tal forma que ele seja participante de seu processo terapêutico. Considero a psicoterapia, em sentido amplo, como atividade cuja intenção é aliviar o sofrimento inerente aos conflitos do viver, por meio do desenvolvimento das 
capacidades de cada indivíduo para lidar com os mesmos. E, também, como um processo de expansão de espaços psíquicos para promover simbolização e pensamento.

Parto do pressuposto de que não existe uma única verdade e de que a defesa de um único ponto de vista é uma forma de exercer o poder, como nos ensina Foucault (1994).A questão é em que sentido determinadas práticas podem contribuir para a criação de uma maior autonomia e liberdade. Liberdade, para desenvolver e 'inventar' sua própria subjetividade (Ferreira, 2007). A clínica psiquiátrica, de caráter descritivo, toma a fala do paciente no sentido de signos médicos para encontrar um sentido preposto em seus manuais e identificar um diagnóstico -isso em detrimento da alteridade revelada nos sintomas (Bursztyn, 2008).Na escuta psicanalítica, os sintomas mostram algo singular daquele paciente.

Em ambos os ambulatórios em que dou supervisão (PROPSIC, AMBORDER) atendemos pessoas encaminhadas para psicoterapia que, muitas vezes, não sabem nem o porquê foram parar lá. São poucas as que chegam por demanda própria. Em geral, são encaminhadas por outros ambulatórios dentro do complexo hospitalar, da rede pública, ou mesmo de outros setores da psiquiatria.São pessoas que sofrem, procuram uma solução e não tem nenhuma, ou pouca conscientização de seus conflitos pessoais. A referência delas é o modelo médico e, a maioria é encaminhada justamente por terem esgotado a possibilidade de tratamento na instituição médica. Por exemplo, pacientes encaminhados do ambulatório de transtornos afetivos por apresentarem depressões refratárias, outros do CAPS por dificuldade de adaptação às propostas de terapêutica em grupo, outros considerados pelos médicos, com dificuldade de adesão aos tratamentos clínicos, por questões emocionais, quase sempre entendida como depressão. É comum observarmos a necessidade da psicoterapia para depois a pessoa poder aceitar e seguir uma ajuda medicamentosa. Existem cada vez mais evidências de que a combinação de psicoterapia e tratamento medicamentoso é proveitosa para muitos pacientes (Gabbard, 2006).

Assim, boa parte da atividade é dedicada a procurar esclarecer em que consiste nossa abordagem, que não temos receitas, que vamos precisar de uma parceria, da formação de uma dupla para poder entender e ajudar. Nem sempre os pacientes são medicados e algumas vezes, à medida que se desenvolve a psicoterapia, o diagnóstico fica mais claro e ele é encaminhado a um 
tratamento psiquiátrico clínico concomitante. A não aceitação de um transtorno, a resistência a um tratamento, pode ser entendido ao longo de movimentos transferenciais e contratransferenciais - método essencialmente psicanalítico.

Procuro passar para meus alunos, médicos e psicólogos, a importância da escuta do paciente sob um outro vértice, onde o sujeito se constitui a partir de seu desenvolvimento afetivo, sua história pessoal e de seu grupo originário. E, quem observa, também é um outro sujeito que constitui e modifica um campo dinâmico (Baranger\&Baranger, 1969). O ponto essencial é poder configurar esse campo relacional para utilizar os aspectos intuitivos e emocionais do terapeuta como instrumento de ressonância para a compreensão do paciente-analisando.

O terapeuta precisa escutar o som, ruído ou não, que emerge desse encontro de subjetividades que tem um aspecto até certo ponto familiar e outro não. No momento da escuta, a teoria, o desejo e a memória do terapeuta devem estar opacificadas como nos ensina Bion (1963). Ao mesmo tempo o ouvinte tem que conhecer a própria história para discernir o que é seu e o que é do outro, como sujeitos separados. Assim, sua auto-reflexão é fundamental para este trabalho. Na medida em que se trata de uma experiência vivida por meio desse encontro de subjetividades, o que se fala é criado pela interlocução da dupla e isto possibilita a recontextualização das experiências do paciente-analisando, o que pode ser terapêutico. Assim alguns aspectos emocionais clivados do sujeito são passíveis de serem integrados à personalidade (Ogden, 1996).

Para pensarmos o que seriam esses aspectos clivados, lembro-me sempre de Ogden em seu livro, Os sujeitos da Psicanálise. Esse autor destaca que desde Freud temos que o sujeito se constitui em uma relação dialética, seja entre duas instâncias, consciente e inconsciente (Freud),seja entre posição esquizo-paranóide e depressiva PS - PD (Klein e Bion), seja no espaço potencial constituído pela mãe e seu bebê para o desenvolvimento do sujeito diante da dialética entre a experiência de estar-uno (at-one-ment) e estar separado. Assim, nos últimos cinquenta anos a técnica passou a se dedicar ao estudo da interdependência entre sujeito e objeto, ou seja, o campo da intersubjetividade.

Dessa interrelação de subjetividades - do terapeuta e paciente- seria criado o terceiro analítico que é um processo sempre mutante, dialético que permite que cada participante da dupla se 
constitua e se separe. Isso quando possível depois de algum tempo de encontros demarcados pelo ritmo das presenças e ausências da dupla.

Acredito que os avanços na farmacoterapia nos traz à sala de análise pacientes que ali não ficariam se não fossem medicados. Não aguentariam o processo analítico. Portanto, acredito na necessidade e importância do diagnóstico, que incluem uma avaliação descritiva psicopatológica, até psiquiátrica, além da psicodinâmica: o quanto este paciente é semelhante a outros e o quanto é diferente.

O uso do diagnóstico neste campo relacional é mutativo. Lembro, por exemplo, de um rapaz jovem, por volta de seus vinte e poucos anos que nos foi encaminhado com o diagnóstico de transtorno obsessivo compulsivo. Ele estava em tratamento clínico, seu psiquiatra o tinha encaminhado para o CAPS e lá, como apresentasse dificuldade de conviver com os outros pacientes devido a agressividade que o colocava em risco a si e aos outros, foi solicitado uma psicoterapia individual. Ele já estava na fila de um processo neurocirúrgico para aliviar seus sintomas obsessivos quando iniciamos seu tratamento psicoterápico. Ele aderiu a nova proposta, se vinculou ao seu primeiro terapeuta e aceitou as trocas dos terapeutas que ocorrem por motivos institucionais. Aos poucos, esse rapaz com importantes questões narcísicas, porta-voz e reflexo de uma família também com complicações semelhantes as dele, com grande carga de violência, desistiu de fazer o tratamento cirúrgico e foi se desenvolvendo a ponto de conseguir um trabalho que lhe deu oportunidade de se inserir na sociedade.

Ao lado dessa experiência satisfatória do ponto de vista do senso comum, lembro de uma outra paciente encaminhada da enfermaria psiquiátrica do hospital, com o diagnóstico de um transtorno histriônico e/ ou borderline, com várias tentativas de suicídio ingerindo objetos cortantes que precisavam ser localizados por raio $\mathrm{X}$ e retirados cirurgicamente. Com a psicoterapia ela conseguiu trazer à tona sentimentos, medos muito primitivos, porém, a evolução de seu quadro clínico nos fez pensar em um diagnóstico de uma psicose crônica. Apesar do trabalho efetuado,continuou bastante dependente da instituição. Esses casos lançam para nós psicanalistas o desafio de ampliar o escopo do nosso conhecimento em relação aos aspectos mais primitivos do desenvolvimento da mente. 
A prática clínica não pode renunciar ao uso do terapeuta como instrumento de ressonância emocional para promover a elaboração dos aspectos afetivos do paciente. É isto o que temos. Não possuímos marcadores bioquímicos, aparelhos computadorizados que enxergam além (Nemiah, citado por Gabbard, 2006). Temos que contar com nossa própria capacidade de ressonância afetiva que precisa ser desenvolvida.

No momento, reparo que cada vez mais, precisamos estimular que o aluno-psiquiatra ou psicólogo valorize essa capacidade de ressonância como uma forma de produzir conhecimento no contato com o paciente. Para isso precisamos mostrar a importância e os limites do campo transferencial-contratransferencial.

Winnicott (1962) em seu artigo sobre - Os objetivos do tratamento psicanalítico comenta:

Em geral, análise é para aqueles que querem, necessitam e podem tolerá-la. Quando me defronto com o tipo errado de caso, me modifico no sentido de ser um psicanalista que satisfaz, ou tenta satisfazer, as necessidades de um caso especial. Acredito que este trabalho não-analítico pode ser melhor feito por um analista versado na técnica psicanalítica clássica.

Mais adiante, ele afirma: "se nosso objetivo continua a ser verbalizar a conscientização nascente em termos de transferência, então estamos praticando análise; se não, somos analistas praticando outra coisa que acreditamos ser apropriada para a ocasião. E por que não haveria de ser assim? (Winnicott, 1983 p.154 - 155)

\section{Referências}

American PsychiatricAssociation. (APA), (2015). Manual Diagnóstico e Estatísticode Transtornos MentaisDSM5 (5 ${ }^{\text {a }}$ ED.). Porto Alegre: Artmed.

Baranger, M \&Baranger, W. (1961-62). "La situacion analítica como campo dinâmico. Revista Uruguaia de Psicoanalisis", IV, 1-3-54 In Baranger, M \&Baranger, W. Problemasdel campo psicoanalitico. Buenos Ayres, Kargieman, 1969.

Bursztyn,D.C. (2008) "O tratamento da histeria nas instituições psiquiátricas: um desafio para a psicanálise". In Estudos e Pesquisas em Psicologia, UERJ, 8(1), pp126-135. 
Costa Pereira, M.E. (2009). "Kraepelin e a questão da manistestação clínica das doenças mentais". In Revista Latino-americana de Psicopatologia Fundamental. 12(1), 161-66.

Dalgalarrondo, P.\& Vilela, W.A. (1999). “Transtorno borderline: história e atualidade”. In Rev. Latino-americana de Psicopatologia Fundamental, II,2,52-7.

Dunker, C.I.L., \&Kyrellos Neto, F. (2011). “A Psicopatologia no limiar entre psicanálise e psiquiatria: estudo comparativo sobre o DSM”. In Vínculo, 8(2), 1-15.

Ferreira Neto, J.L. (2007). “Artes da Existência: Foucault, a Psicanálise e as PráticasClínicas”. In Psicologia: Teoria e Pesquisa: 23; 2, pp. 177-184.

Foucault, M. (1994). Microfísica do poder. Org e trad. Machado, R. Rio de Janeiro, Ed. Graal, $4^{\mathrm{a}}$ ed.

Gabbard G. (2006) Psiquiatria psicodinâmica na prática clínica. Porto Alegre, Artmed.

Green, A. (1988) Sobre a loucura pessoal. Rio de Janeiro, Imago.

Nishikawa, E; Fiore M.L.M \&Hardt,O. (2017) "Histeria e Borderline: Mo(vi)mentos da clínica psicanalítica”. In Jornal de Psicanálise, 50 (93), 273-289.

Ogden, T.H. (1996) “Tornar-se sujeito”. In Os sujeitos da psicanálise. São Paulo, Casa do Psicólogo, p. 1-10.

Pessotti, I. (1999). Os nomes da loucura. São Paulo, Ed.34.

Pio-Abreu, J.L. (2013) "Psicopatologia e classificação em psiquiatria". In Revista debates em psiquiatria, 3(1), 6-15.

Winnicott, D W. (1959-1964/1983). “Classificação: existe uma contribuição psicanalítica à classificação psiquiátrica?". In O ambiente e os processos de maturação: estudos sobre a teoria do desenvolvimento emocional. Porto Alegre, Artmed, p. 114-127.

Winnicott, D W. (1959-1964/1983). “Os objetivos do tratamento psicanalítico” (1962). In $O$ ambiente e os processos de maturação: estudos sobre a teoria do desenvolvimento emocional.Porto Alegre, Artmed, p.154-5.

Yazigi, L.; Fiore M.L.M.\& Lorenzetti, L.A. (2018). "Sistemas classificatórios de avaliação da personalidade: CID, DSM e escalas semi-estruturadas de personalidade". In Avaliação psicológica da inteligência e da personalidade. Org. Hutz, C.S; Bandeira, D.R. \&Trentini, C.M. Porto Alegre, Artmed, pp.300-11. 